\title{
O PROBLEMA DA ADEQUAÇÃO DOS PARÂMETROS DO QUADRO EUROPEU COMUM DE REFERÊNCIA E "A NECESSIDADE DE EMERGIR COMO OS OUTROS DE NÓS MESMOS" 1,2
}

\author{
The Problem of Parameter Adequacy in the Common European Framework of \\ Reference for Languages, and the Need to "Emerge as Others of Ourselves"
}

\author{
Elaine C. ROSCHEL NUNES, UFPR $^{3}$ \\ Franziska LORKE - CELIN, UFPR ${ }^{4}$
}

\begin{abstract}
RESUMO: A proposta deste artigo é apresentar as recomendações do Quadro Comum Europeu de Referência (doravante: QCER) e discutir sua aplicabilidade. A princípio, apresentaremos os objetivos gerais do QCER e teceremos críticas às contradições do documento. Partindo da visão pós-colonial, apresentaremos reflexões e questionamentos que devem estar presentes durante a determinação dos objetivos educacionais para o ensino de línguas estrangeiras. Com foco nesse contexto e como base para essa discussão, serão utilizados, como referência, os conceitos da obra de Homi K. Bhabha (2010). Por fim, apresentaremos como conclusão as possíveis consequências e perspectivas para a sala de aula.
\end{abstract}

PALAVRAS-CHAVE: Quadro Comum Europeu de Referências; Diversidade; Ensino de língua estrangeira.

ABSTRACT: The purpose of the following article is to introduce the recommendations represented in the Common European Framework of Reference for Languages (CEFR) and discuss their applicability. The main objectives of the CEFR will be presented and inherent contradictions of the document criticized. Using postcolonial theory, important questions for the determination of educational goals in foreign language teaching will be posed. Focusing on this context, the work of Homi K. Bhabha (2010) will be used as basis for the discussion. In the end a conclusion of possible consequences and perspectives for the classroom will be presented.

KEYWORDS: The Common European Framework of Reference for Languages; Diversity; Foreign Language Teaching.

\section{INTRODUÇÃO: OBJETIVOS DO QUADRO COMUM EUROPEU, SUAS IMPLICAÇÕES E INCONSISTÊNCIAS}

\footnotetext{
${ }^{1}$ Bhabha, 2010, p. 69.

${ }^{2}$ Artigo apresentado como trabalho de conclusão da disciplina: Estudos em Linguística Aplicada III /2011 - Profa. Clarissa Jordão.

${ }^{3}$ Doutoranda na UFPR.

${ }^{4}$ Professora.
} 
Há muito tempo, aprender uma língua não significa mais decorar vocábulos e usá-los de acordo com o enunciado do exercício. A comunicação, a mediação linguística e a competência cultural são alguns aspectos em evidência na presente fase do ensino de línguas estrangeiras. Todos esses termos vêm sendo discutidos dentro de um contexto histórico-cultural específico, no qual as fronteiras e identidades são repensadas. Em meio aos novos desafios deste momento histórico, o professor de língua estrangeira se depara com a "fixidez" 5, ainda presente, na determinação das diretrizes para o desenvolvimento de seu trabalho.

Um dos instrumentos que apontam diretrizes para o trabalho do professor de língua estrangeira é o QCER. Tanto livros didáticos como cursos de línguas e testes oficiais em língua estrangeira estão orientados para os níveis de aprendizagem descritos nesse documento. Instituições oficiais para o ensino de alemão como língua estrangeira $^{6}$, por exemplo, consideram o QCER como base no Brasil. Dessa forma, o documento possibilitou uma padronização dos níveis de proficiência dos alunos. Também as provas para o acesso às universidades alemãs estão baseadas nesse documento (QUETZ, 2003, p.146). A adoção do QCER é justificada pelas instituições pela facilidade de avaliação, nivelamento e comprovação do conhecimento adquirido.

De fato, considerando os diferentes níveis que definem a competência linguística do indivíduo e determinam o conteúdo de um curso de línguas por meio da descrição das habilidades a serem desenvolvidas, o QCER aparece como uma forma de unificar o sistema de ensino de línguas pela delimitação de objetivos específicos para cada nível de aprendizagem. Assim, independentemente da instituição ou do país em questão, a descrição dos objetivos de aprendizagem a serem alcançados é feita de maneira generalizada em esquemas comuns a todos, com base nos níveis de referência.

Os seis níveis partem de três níveis gerais, representados a seguir:

\begin{tabular}{|c|c|c|}
\hline A & B & $\mathrm{C}$ \\
\hline Utilizador elementar & Utilizador independente & Utilizador proficiente \\
\hline A1 & B1 & C1 \\
\hline Elementar & Vantagem & Autonomia \\
\hline
\end{tabular}

\footnotetext{
${ }^{5}$ Termo utilizado por Bhabha (p.68ff, 2010) em vários trechos de seu livro para designar o "estagnado", "fixo".

${ }^{6}$ Como profissionais da área de alemão como língua estrangeira, utilizaremos alguns exemplos e a literatura referente ao nosso ramo de atuação.
} 
Figura 1: Níveis Comuns de Referência Fonte: QCER, 2011, p.48

Para cada um desses níveis são definidas capacidades, perfis ideais que devem ser alcançados para se avançar no estudo da língua. ${ }^{7}$ Apenas para ilustrar a descrição das capacidades, destacamos a seguir o nível do utilizador independente:

Quadro 1: Níveis Comuns de Referência em escala global.

\begin{tabular}{|l|l|l|}
\hline Utilizador independente & B2 & \begin{tabular}{l} 
É capaz de compreender as ideias principais em \\
textos complexos sobre assuntos concretos e \\
abstractos [sic], incluindo discussões técnicas na \\
sua área de especialidade. É capaz de comunicar \\
com um certo grau de espontaneidade e de à- \\
vontade com falantes nativos, sem que haja tensão \\
de parte a parte. É capaz de exprimir-se de modo \\
claro pormenorizado sobre uma grande variedade \\
de temas explicar um ponto de vista sobre um \\
tema da actualidade [sic], expondo as vantagens e \\
os inconvenientes de várias possibilidades. \\
\hline É capaz de compreender as questões principais, \\
quando é usada uma linguagem clara e \\
estandardizada e os assuntos lhe são familiares \\
(temas abordados no trabalho, na escola e nos \\
momentos de lazer, etc.). É capaz de lidar com a \\
maioria das situações encontradas na região onde \\
se fala a língua-alvo. É capaz de produzir um \\
discurso simples e coerente sobre assuntos que lhe \\
são familiares ou de interesse pessoal. Pode \\
descrever experiências e eventos, sonhos, \\
esperanças e ambições, bem como expor \\
brevemente razões e justificações para uma \\
opinião ou um projecto [sic].
\end{tabular} \\
\hline
\end{tabular}

Fonte: QCER, 2001, p.49.

Para o alcance dos objetivos propostos pelo QCER, é preciso generalizar e fixar padrões, bem como taxar o aprendiz na escala de capacidades e competências que nem sempre se revelam praticáveis, por exemplo, ao defini-lo como "Utilizador independente". Este será "capaz de comunicar com um certo grau de espontaneidade [...] com falantes nativos, sem que haja tensão de parte a parte. É capaz de usar a língua de modo flexível e eficaz para fins sociais, acadêmicos [sic] e profissionais." (QCER,

\footnotetext{
${ }^{7}$ Maiores informações e apresentação detalhada dos níveis: Quadro Europeu Comum de Referência para as Línguas Aprendizagem, ensino, avaliação, 2001. Os descritores das atividades comunicativas se situam no Capítulo 4 e os descritores dos aspectos da proficiência relacionados com competências específicas se situam no Capítulo 5.
} 
2001, p.49). A nosso ver, termos como "um certo grau de espontaneidade" e "sem tensão" são critérios difíceis de se considerar na avaliação ou na classificação dos "padrões" definidos nas grades do QCER.

No QCER, tudo que se refere a "sou capaz de realizar" na língua estrangeira está exposto em uma grade para avaliação ${ }^{8}$. O aluno do nível A1, por exemplo, deve ser capaz de avaliar se possui "um repertório básico de palavras e expressões simples relacionadas com aspectos pessoais e situações concretas determinadas". Ou se, como aluno $\mathrm{C} 1$, ele é dotado de "um bom controlo [sic] de uma ampla gama de linguagem, permitindo-lhe seleccionar [sic] determinada formulação para se exprimir num estilo claro sobre um vasto conjunto de tópicos gerais, acadêmicos [sic], profissionais ou recreativos, sem ter que restringir aquilo que quer dizer." Ou como C2 se é "capaz de interagir com facilidade e habilidade, captando e usando pistas não verbais e entoacionais aparentemente sem esforço" (QCER, 2001, p.57).

Será que se pode medir o alcance dessas metas, ou perceber o desenvolvimento das capacidades e competências em questão sem contradições e falsos pareceres? E ainda, essas mesmas metas definidas para o C2 não seriam decisivas nos níveis iniciais? Parece difícil definir tão categoricamente o uso de recursos que podem estar sempre presentes na interação 9 . E mais difícil ainda será medir as metas atingidas sem considerar o todo, complexo e contingente.

De forma paradoxal, a imprecisão ${ }^{10}$ dos descritores, ao mesmo tempo que abre um leque de possibilidades, representa uma postura limitadora, uma vez que pretende "encaixar" as capacidades do aprendiz em grades e padrões preestabelecidos. Mesmo sendo destacado em várias passagens no documento que o processo de aprendizagem é "contínuo e individual" ou que "qualquer tentativa para definir os 'níveis' de proficiência seria de certo modo arbitrária" (QCER, p.40), o documento fixa capacidades em seus descritores que são adotadas como referência para a criação de material didático, avaliação e ensino.

Não pretendemos questionar a necessidade de diretrizes ou a definição de critérios para avaliação, mas sim a forma como lidamos com elas. Com a mesma atitude

\footnotetext{
${ }^{8}$ Além da escala global no QCER, são definidos contextos de utilização (lugar, instituições, pessoas, objetos, acontecimentos, operações, textos) a partir das áreas de interesse e de domínios específicos (privado, público, profissional e educativo). A partir daí, são fornecidas escalas exemplificativas para cada nível de aprendizagem. Depois de definidas as atividades e as escalas exemplificativas, o QCER define as capacidades do aprendiz a partir dos níveis A, B e C.

${ }^{9}$ Veja também: Bredella (2003, p.45ff)

${ }^{10}$ O próprio tradutor do documento para o alemão, Quetz (2003), afirma que os descritores apresentam categorias subjetivas para caracterizar uma capacidade, o que dificulta uma avaliação objetiva do conteúdo proposto.
} 
de crentes fiéis a uma doutrina, aplicamos e adotamos parâmetros, que muitas vezes nem se encaixam em nossa realidade. Antes de tudo, é preciso flexibilidade para lidar com o vago, com o novo e com as mudanças que ocorrem a cada segundo.

Exatamente por isso, acreditamos ser impossível determinar o sucesso de uma interação comunicativa seguindo apenas parâmetros como os apresentados nos descritores do QCER. Partindo do pressuposto de que "as competências comunicativas em língua são aquelas que permitem a um indivíduo agir utilizando especificamente meios linguísticos" (QCER, 2001, p.31 - grifo nosso), parece difícil definir a coerência ou transparência de um assunto ou de uma formulação em contextos diferentes e com sujeitos diversos. Além disso, a utilização de outros elementos que participam do jogo na comunicação (até mesmo os extralinguísticos) não é considerada, justamente por ser impossível prever contextos e situações. Quetz (2003) expõe um interessante exemplo referente à "simples" tarefa de "fazer compras", associada a níveis iniciais. Essa ação pode exigir em alguns contextos uma grande competência linguística, pois pode envolver negociação, discussão sobre preços, qualidade e disponibilidade da mercadoria; em outros, a ação corresponde a simplesmente tirar o produto da prateleira e se dirigir ao caixa, sem precisar dizer uma só palavra, como ocorre em um supermercado europeu (QUETZ, 2003, p.152).

Apesar de o QCER mencionar a importância das estratégias comunicativas, dos gestos e da linguagem corporal, não há como determinar uma progressão estanque para estes elementos e nem definir de forma abrangente que tipo de "estratégias e marcadores linguísticos de relação social ou regras de delicadeza" 11 seria adequado para qual nível específico. Como o próprio QCER descreve, "a necessidade e o desejo de comunicar surgem numa situação específica e a forma e o conteúdo da comunicação são uma reacção [sic] a essa situação (QCER, 2001, p.75).

Na verdade, o QCER possui um cunho político, criado sob negociações, revisões e processos, ou seja, dentro de seu próprio quadro específico de referências (EDMONSON, 2003, p.67). Para a redação do documento, um grupo de pesquisadores franceses e ingleses - com o apoio de um grupo suíço para o tema "avaliação" - reuniuse e definiu as linhas mestras do Quadro. Apesar de vários países terem contribuído com discussões, percebe-se por meio da própria bibliografia do QCER uma forte tendência de concentração nas pesquisas dos países dos grupos envolvidos mais diretamente

\footnotetext{
${ }^{11}$ Tais elementos são apresentados dentro dos descritores para “Adequação Sociolinguística” (QCER, 2001, p.172f).
} 
(CHRIST, 2003, p.57). Além disso, mesmo apresentando-se como "democrático" e "neutro", fica evidente o plano político como base para as linhas mestras do QCER:

Um Quadro de Referência aberto e 'neutro' não implica, evidentemente, uma ausência
de política. Ao propor um Quadro deste género [sic], o Conselho da Europa não está,
de maneira nenhuma, a afastar-se dos princípios [...] que o Conselho de Ministros
dirigiu aos governos-membros. (QCER, 2001, 42).

Um dos objetivos principais para a criação desse documento político é o incentivo ao ensino-aprendizado das línguas europeias na constituição do cidadão europeu, para que, assim, seja possível "conseguir maior unidade entre todos os seus membros", objetivo a ser atingido "com a adopção [sic] de uma acção [sic] comum na área da cultura" ${ }^{\prime \prime}$.

Segundo Altmayer (2004, p.1), a criação de medidas políticas e econômicas precisa ser reforçada, como se a "Europa precisasse ser consolidada nas cabeças e nos corações das pessoas; alemães, franceses, dinamarqueses e poloneses precisam se tornar europeus" 13 . Contudo, como o próprio autor afirma, a almejada identidade europeia ainda é um "ideal para o futuro" ${ }^{14}$. E seria mesmo possível encorajar os europeus a aprender outras línguas como meio de melhorar o entendimento entre culturas? ${ }^{15}$ Com base nessa pergunta, podemos levantar vários aspectos polêmicos para discussão e reflexão. Em virtude da dimensão da discussão que nos propomos realizar neste artigo, vamos nos concentrar em algumas formulações do QCER e suas consequências para a sala de aula.

Na verdade, o sentido de uma ação comum é justificado por seu cunho político. Da mesma forma, o incentivo ao aprendizado das línguas tem seu viés políticoeconômico fundado na necessidade de possibilitar o reconhecimento de qualificações linguísticas em todo o território europeu. Ao adquirir "um conhecimento das línguas de outros Estados-membros (ou de outras comunidades no seio do seu próprio país), assim como as capacidades para o uso dessas mesmas línguas", acredita-se possibilitar uma “enorme mobilidade internacional” e "uma cooperação mais próxima” (QCER, 2001, p.21).

Tal cooperação é vinculada a conceitos de "tolerância recíproca" e ao "respeito pela identidade", bem como à "diversidade cultural" por meio de uma "comunicação internacional mais eficaz" (cf. QCER, 2001, p.22). Esses conceitos, ativos no

\footnotetext{
${ }^{12}$ QCER: Tradução portuguesa, 2001, p.20.

13 Tradução nossa: "Europa muss in den Köpfen und Herzen der Menschen verankert werden, aus Deutschen, Franzosen, Dänen oder Polen müssen Europäer werden“ (Altmayer, 2004, p.1).

${ }^{14}$ Segundo o autor:"Eine solche europäische Identität aber ist derzeit noch Zukunftsmusik" (Altmayer, 2004, p.1).

${ }^{15}$ Edmonson (2003, p.68) tece uma crítica aos interesses políticos por trás do QCER.
} 
pensamento neoliberal, sustentam uma visão de cultura e identidade que se baseia em elementos fixos, como se estes fossem completos e claramente definidos. De fato, esses termos podem ser abordados de diferentes maneiras, de acordo com a perspectiva adotada, e serem usados para justificar a opção por algumas decisões políticas. Por exemplo, no ensino de línguas: ao definir um currículo comum, ao estabelecer se uma língua será ou não oficialmente ensinada, ou ao se determinar pré-requisitos para um visto (entre eles, um certificado de proficiência na língua).

Como justificativa para a criação de parâmetros com base em uma moldura universalista, o próprio Conselho Europeu enxerga a necessidade de esclarecer a função do termo Comum de Referência utilizado em sua nomenclatura, cuja intenção: "não é nem formular os objectivos [sic] que os utilizadores devem atingir, nem os métodos que devem usar o trabalho" (QCER, 2001, p.20). Ao contrário, o QCER deve contribuir "para promover uma cidadania democrática" (op.cit.). Notamos aqui um paradoxo, pois ao definir as finalidades e as funções do QCER, o Conselho da Europa procura criar uma política geral de línguas que sirva de base para todos, montada nos padrões da Europa Ocidental. Esta, aliás, foi uma das críticas feita por vários autores que analisaram o QCER: o "eurocentrismo" ocidental presente no documento ${ }^{16}$, ou seja, apresentando a Europa como referência e base, sem considerar características específicas locais de onde ele seria adotado. ${ }^{17}$

Com efeito, notamos que a criação do QCER traduz a necessidade arraigada dos sujeitos de classificar, denominar, categorizar as coisas, os processos. Tal atitude tem como base a crença de que ao nivelar e generalizar modelos, "facilitam-se" o processo de avaliações e a determinação de objetivos, como forma de padronizar e controlar. Assim, cria-se uma "base única" de diretrizes para o ensino de línguas. O problema é que, na prática, esta justificativa não basta.

Tanto que o desfecho do capítulo sobre os descritores do QCER pondera o seguinte:

Mas a questão complica-se pelo facto de estar envolvida uma enorme quantidade de padrões. Tal acontece, porque, para além do problema do modo de avaliação utilizado e do grau de interpretação comum dos níveis feita pelos professores em qualquer contexto, cada ano escolar, em cada tipo de escola, em cada região diferente do ponto

\footnotetext{
${ }^{16} \mathrm{Na}$ obra "Der Gemeinsame europäische Referenzrahmen für Sprachen in der Diskussion“(2003), são apresentados 23 artigos sobre a relação do Quadro com a prática, as perspectivas de uso e pesquisa com base no documento. Vários autores como o próprio tradutor do documento para o alemão (Quetz,, p.152) apontam para as incoerências do texto. $17 \mathrm{O}$ foco é o contexto da língua-alvo como forma de criar um documento abrangente, definindo a Europa como base: "Isto significa que as categorias usadas para descrever aquilo que os aprendentes são capazes de fazer em diferentes contextos de uso devem poder relacionar--se com os contextos da língua-alvo de diferentes grupos de aprendentes no seio da generalidade da população-alvo" (QCER, 2001, p.45).
} 
de vista educativo, constituirá naturalmente o seu próprio padrão (QCER, 2001, p. 72).

$\mathrm{Na}$ verdade, os caminhos políticos nem sempre conduzem para uma clara definição dos objetivos a serem alcançados na prática de ensino. No dia-a-dia, cada instituição e cada profissional devem fazer suas escolhas, com base na sua realidade.

Há autores, entretanto, que consideram o QCER um importante meio de orientação (QEVEHA, 2008, PRAXEDES, 2008), uma vez que, a partir daí, foram levantadas discussões referentes a importantes aspectos, como a mediação linguística ${ }^{18}$ e os objetivos comunicativo-culturais. Apesar disso, não podemos negar o caráter hegemônico e fixo em modelos ideais que nem sempre se encaixam no contexto específico de cada país ou instituição.

Como política de integração europeia, o intuito desse Quadro prevê ainda uma busca pelas "culturas em contato", em um processo de "salvaguarda do continente" (PRAXEDES, 2008). Por meio de intervenções políticas, tenta-se manipular e planejar o uso das línguas. De fato, a ideia de proteção de culturas evidencia a visão de um Estado-nação que enxerga a língua como patrimônio,

que representa a diversidade linguística e cultural na Europa e constitui uma valiosa fonte comum que convém proteger e desenvolver, sendo necessários esforços consideráveis no domínio da educação, de modo a que essa diversidade, em vez de ser um obstáculo à comunicação, se torne numa fonte de enriquecimento e de compreensão recíprocos (QCER, 2001, p.20).

Mais uma vez, o QCER apresenta uma contradição: o mesmo processo que tenta criar culturas acabadas em molduras universais, a serem resgatadas, protegidas e salvas, como se estivessem sob risco de se perderem; deve também possibilitar a diversidade, como fonte de enriquecimento que promove a compreensão entre as culturas e não se interpõe como obstáculo à comunicação.

Do ponto de vista pós-colonial, quando se fala em diversidade cultural, por exemplo, vem-nos à tona a questão das diferenças e da zona de fronteira entre as culturas. Essas são algumas questões que discutiremos adiante com base nos termos adotados no QCER. De antemão, já lançamos as perguntas: pode-se mesmo falar em um harmonioso contexto multicultural? O que ocorre no entre-espaço entre culturas?

Esse entre-espaço não é abordado diretamente no QCER. Em nossa opinião, esta discussão é necessária, assim como, é necessário que se reflita sobre a diferença de

\footnotetext{
${ }^{18}$ Sobre a mediação linguística e tradução: Bohunovsky (2009)
} 
culturas não como algo encaixado numa "moldura universalista" ${ }^{19}$, afinal não existe verdade única e nem uma "moldura acabada" de cultura. Estamos, sim, em constante processo de negociação. Na prática, é "até mesmo impossível tentar e conseguir juntar diferentes formas de cultura, pretendendo que elas possam coexistir facilmente" (RUTHERFORD, 1996, p.36).

O QCER aborda a "consciência cultural" como processo que permite distinguir as diferenças e semelhanças entre "o mundo de onde se vem" e o "mundo da comunidadealvo" e a percepção da "diversidade regional e social dos dois mundos" e, com isso, acaba reforçando fronteiras, em vez de "ultrapassar relações estereotipadas" (cf. QCER, 2001, p.150). Quando separamos aspectos da língua alvo e da cultura de origem para que o aluno aprenda a distingui-los, já estamos criando molduras acabadas de cultura.

Enfim, em outras palavras, se corrermos o risco de enxergar o QCER como algo verdadeiramente fabuloso e não questionarmos nossa vontade de verdade (FOUCAULT, 1970, p.17), produziremos um sistema baseado em conceitos fixos, sem relevância para nosso contexto real. Apoiando-nos nas ideias de Bhabha (2010), devemos reconhecer que, no "momento híbrido de mudança, o valor transformacional reside na rearticulação, ou tradução, de elementos que não são nem o um nem o outro, mas algo a mais, que contesta os termos e territórios de ambos" (Ibid., p. 55), sendo este ponto de encontro de extrema relevância para os professores de uma língua estrangeira.

O QCER adota, entre outros, o conceito da diversidade cultural como base, porém, tal fato se mostra problemático, porque não levanta a questão de que o ensino e a aprendizagem de línguas estão conectados em um movimento de hibridização da própria identidade.

Diante deste momento específico e como parte de nossa reflexão sobre um Quadro de Referências europeu em solo brasileiro, analisaremos o QCER em detrimento às noções de diversidade e diferença, abordadas por Homi Bhabha (2010) em sua obra $O$ Local da Cultura.

\section{REFLEXÕES E QUESTIONAMENTOS COM BASE NA OBRA DE HOMI BHАBНА}

\footnotetext{
${ }^{19}$ Bhabha em entrevista a Rutherford (1996, p.37)
} 
Nesta sessão, retomaremos as questões levantadas na primeira parte do trabalho. Questões como: Pode-se mesmo falar em um harmonioso contexto multicultural? O que ocorre no entre-espaço entre culturas? O QCER considera este aspecto?

Dentre os atuais teóricos envolvidos com a polêmica definição do termo "cultura", destacamos Homi Bhabha, crítico indo-britânico que apresenta importantes reflexões sobre os temas culturais da atualidade. Como indivíduo marcado pela própria experiência de hibridização e deslocamento cultural, Bhabha tece reflexões sobre o local desestabilizado da cultura e sem significados fixos.

Em sua obra $O$ local da cultura (2010), Bhabha explica a diferença entre os termos diversidade e diferença cultural, dentro do contexto pós-colonial de pensamento ${ }^{20}$ :

\begin{abstract}
A diversidade cultural é um objeto epistemológico - a cultura como objeto do conhecimento empírico - enquanto a diferença cultural é o processo de enunciação da cultura como "conhecível", legítimo, adequado à construção de sistema de identificação cultural (2010, p.62).
\end{abstract}

Para esse autor, é como se a diferença cultural fosse o processo de significação, que "discrimina e autoriza a produção de campos de força, referência, aplicabilidade e capacidade" (Bhabha, 2010, p.62).

Bhabha (loc. cit.) descreve diversidade como o processo de "reconhecimento de conteúdos e costumes culturais pré-dados, mantida em um enquadramento temporal relativista, que dá origem a noções liberais de multiculturalismo, de intercâmbio cultural ou da cultura da humanidade". Para esse autor, a utopia da idéia de uma "identidade coletiva única" faz parte deste contexto, além da "retórica radical da separação de culturas" (loc. cit.).

A diversidade é vista, portanto, como "uma coisa boa e positiva que deve ser incentivada" (RUTHERFORD, 1996, p.35). Em sociedades pluralistas e democráticas, é comum ouvir dizer "que elas [as sociedades] podem incentivar e acomodar a diversidade cultural", como se pudéssemos colecionar culturas e apreciá-las. Nesse meio, todos são categorizados em grupos.

\footnotetext{
${ }^{20}$ Pelas dimensões do artigo, não teceremos considerações mais profundas sobre o pensamento pós-colonial. O próprio termo pode levar a uma série de discussões e abordagens diferentes. Para esclarecer nosso ponto de partida, vale citar Bhabha, segundo o qual: "A perspectiva pós-colonial nos força a repensar as profundas limitações de uma noção 'liberal' consensual e conluiada de comunidade cultural. Ela insiste que a identidade cultural e a identidade política são construídas através de um processo de alteridade" (2010, p.244). Nesse processo, "o discurso da minoria revela a ambivalência intransponível que estrutura o equívoco momento histórico" (Ibid., p. 222). O momento póscolonial reflete ainda uma resposta das margens ao centro, em que " a identidade é reivindicada a partir de uma posição de marginalidade ou de uma tentativa de ganhar o centro" (Ibid., p.247). Este é o "tempo que desestabiliza a ética liberal da tolerância e a moldura pluralista do multiculturalismo"(loc.cit.).
} 
O uso do termo "diversidade cultural" pelo Conselho Europeu acaba reforçando essa ideia da divisão, caracterizando "povos e culturas" em grupos uniformes. Da mesma forma, a estratégia de classificar os aprendizes de idiomas em parâmetros comuns nos níveis A1 até C2 nas línguas europeias é uma forma de uniformização que nem sempre corresponde a todos os indivíduos e contextos.

Na tentativa de controlar o processo dinâmico da articulação da diferença cultural, o multiculturalismo propaga a diversidade cultural, que classifica e categoriza culturas e povos. A diferença cultural, por outro lado, representa um espaço produtivo de construção de cultura como base no espírito de alteridade ou outridade (cf. RUTHERFORD, 1996, p.36).

Temos que aprender sim a visualizar o outro, sem encaixá-lo em molduras. Afinal, nada é constante e permanente. Em contínuo processo de troca e negociação, podemos constatar que nenhuma cultura é também completa. De acordo com Bhabha (2010, p.228), “a questão da diferença cultural nos confronta com uma disposição de saber ou com uma distribuição de práticas que existem lado a lado, [...] designando uma forma de contradição ou antagonismo social que tem que ser negociado, em vez de negado".

A cultura, sob essa perspectiva, está sempre traduzindo símbolos em um incessante processo de construção de sentidos. Entre identificações fixas, criadas para categorizar, abre-se "espaço para um hibridismo cultural que acolhe a diferença sem uma hierarquia suposta ou imposta" (BHABHA, 2010, p.12). As formas de identidade nesse meio, além de incompletas ou abertas à tradução cultural, nunca se revelam puras e totais, pois vivem em um processo de interpretação cultural, que é "efeito da perplexidade do viver nos espaços liminares da sociedade nacional” (Ibid., 227 et seq. ).

Nesse âmbito, considerando as premissas de Bhabha, podemos concluir que o QCER, proposto pelo Conselho Europeu, tem sua base firmada em conceitos fixos e pré-dados. O entre-lugar - que é o "lugar" de encontro entre os grupos, um meio de tradução e negociação ao vislumbrar diferentes histórias - não merece destaque no documento. Tal processo de negociação só pode ocorrer em um espaço, onde o significado não seja fixado, mas reinventado o tempo inteiro (lugar chamado por Bhabha de "terceiro espaço" ou "entre-lugar"). Se transferirmos essa ideia para o ensino de línguas, podemos entender esse espaço como a chance de não fixar polaridades, de 
descobrir os vários “eus", no dizer de Bhabha (2010, p.69): “como os outros de nós mesmos".

E o que significa isso? Significa poder se enxergar de diferentes maneiras em diferentes situações, sem fixar modelos. Significa também enxergar o outro além dos problemas de interação que "só emergem nas fronteiras significatórias, onde significados e valores são (mal) lidos ou signos são apropriados de maneira equivocada" (Ibid., p.69).

De fato, nas comunicações em geral, as informações "mal-lidas" refletem uma problemática. Na tentativa de compreender esses fenômenos, observa-se o efeito e não a estrutura do problema. Hoje em dia, fala-se contra o preconceito e o estereótipo, mas não se abre espaço para discussões sobre "um espaço contraditório e ambivalente, no qual as afirmações e sistemas culturais são construídos" (RUTHERFORD, 1996, p.41).

É nesse espaço ambivalente que se constata a diferença cultural; nele, significados ou símbolos não têm unidade ou fixidez. Importante, ao abordar conceitos como cultura e ensino de língua, é refletir sobre o processo de negociação nesse entremeio. Afinal, de acordo com Bhabha (RUTHERFORD, 1996, p.41) "em qualquer luta política particular, novas frentes estão sempre sendo abertas e, se você insistir em relacionar essas frentes novas a velhos princípios, não será realmente capaz de participar delas de um modo criativo, produtivo e pleno".

Ao adotar tal postura, uma nova "aliança" se constitui, a partir daqui precisamos traduzir princípios, expandi-los ou repensá-los. Essa nova área de negociação é a hibridização, o terceiro-espaço que permite a criação de outras posições, ou seja, novas formas de agência. No contexto da educação e, mais especificamente, no ensino de línguas estrangeiras, a agência deve envolver estratégias para conviver com as diferenças e conflitos, que estão presentes e podem acontecer até mesmo como algo positivo no processo de aprendizagem (cf. JORDÃO, 2008, 11). Como Jordão (2000) ${ }^{21}$ expõe: "não se trata de levar ao conformismo ou à revolta, nem de moldar indivíduos para a revolução ou a apatia, mas sim de expô-los à multiplicidade e à contradição, para que o diferente seja visto com bons olhos, como uma possibilidade de criação e não como um inimigo pernicioso a ser destruído".

Alunos e professores devem ser capazes de operar nas fronteiras de um discurso imposto e suas ambivalências, aprendendo a lidar com os conflitos inerentes ao

\footnotetext{
${ }^{21}$ Artigo disponível em: http://revistabrasil.org/revista/ingles/clarissa.htm\#fn2 (último acesso: 12.jan.2010)
} 
processo de aprendizagem, encarando-os como parte do processo e não como algo que deva ser evitado, taxado ou preso em modelos fixos e histórias únicas. Ao deslocar histórias, gerar novas autoridades, por vezes inadequadamente compreendidas, o processo de hibridização cultural gera algo diferente e novo, traduzindo novas formas de sentido e representação. O QCER deixa de explorar esse campo e se prende a uma grade de capacidades orientadas para a produção e avaliação e não para o sujeito híbrido em um movimento contingente e que sente a necessidade de ir além da línguainstrumento para um meio de negociação sem fronteiras.

A nosso ver, a grade de capacidades reflete tais fronteiras no aprendizado. Basta verificar a divisão em competências, horizontal e verticalmente distribuídas, para perceber que, existindo a necessidade de medir e avaliar há a necessidade de um sistema que defina regras ${ }^{22}$. Todavia, qual o sentido de padronizar por meio de um quadro comum, generalizando esquemas de comunicação, que nem sempre vão acontecer de forma prevista e planejada? No próximo tópico, com base nos conceitos levantados, discutiremos estas questões e suas consequências para sala de aula.

\section{CONSEQUÊNCIAS PARA A SALA DE AULA}

Para atingir o objetivo geral de entendimento entre culturas, dentro dos parâmetros do QCER, os participantes do processo de aprendizagem - professor e aluno - têm uma função crucial:

\footnotetext{
Numa abordagem intercultural, é objectivo [sic] central da educação em língua promover o desenvolvimento desejável da personalidade do aprendente no seu todo, bem como o seu sentido de identidade, em resposta à experiência enriquecedora da diferença na língua e na cultura. Cabe aos professores e aos próprios aprendentes reintegrar as várias partes num todo saudável e desenvolvido (QCER, 2001, p.19).
}

O que significa este "todo saudável e desenvolvido"? E qual é o sentido de identidade proposto? Em meio a esse contexto, professor e aluno devem reintegrar as várias partes nesse todo, com base em uma realidade criada, sem conflitos, mas sim "saudável".

Com o intuito de criar essa base comum para a elaboração de programas de línguas, linhas de orientação curriculares, exames, manuais, etc., na Europa, os autores procuraram "descrever exaustivamente aquilo que os aprendentes de uma língua têm de

\footnotetext{
${ }^{22}$ Christ (2003, p. 60) e Barkowski (2003, p.22) criticam a estrutura fixa do QCER em seus artigos.
} 
aprender para serem capazes de comunicar nessa língua e quais os conhecimentos e capacidades que têm de desenvolver para serem eficazes na sua actuação" (QCER, 2001, p.19, grifo nosso). Mas como considerar se a proposta dos descritores criados para o contexto europeu realmente se encaixa na realidade dos alunos, definindo o que eles têm de aprender e de desenvolver para serem eficazes? Como saber se o que é bom para a Europa deve ser adequado para a pessoa Y no país X? (cf. EDMONSON, 2003, p.68).

Concordamos com Barkowski (2003, p.26) quando afirma que as descrições do QCER são fundamentadas numa realidade elitista ideal, sem considerar as intenções comunicativas ou anseios de determinado grupo ou indivíduo. Barkowski (2003) define o modelo como uma tentativa de dividir em porções a competência comunicativa das pessoas, como se a língua fosse um inventário cumulativo de desempenhos. Afinal, como já constatamos, as instituições de ensino têm a necessidade de agrupar, de criar padrões e de medir o conhecimento.

A tentativa de categorização e unificação do QCER foi mais longe nesta meta, ao definir uma escala e premissas sem pretender abordar uma linha teórica específica. A tentativa de não assumir uma posição teórica explícita e de criar uma "democracia plurilinguística" (cf. QCER, 2001, p. 17) tem o intuito de nivelar não somente os parâmetros adequados para cada nível, mas permitir que "gregos e troianos" sejam considerados no documento e, portanto, o aceitem dentro de sua linha.

\footnotetext{
A descrição deve também basear-se nas teorias da competência linguística, se bem que a teoria e a investigação actualmente [sic] disponíveis se mostrem inadequadas para servir de base a uma descrição deste tipo. A categorização e a descrição devem, de qualquer forma, ter uma base teórica. Para além de se relacionar com a teoria, a descrição deve também permanecer amigável - acessível aos que trabalham na área (QCER, 2001, p.45).
}

Realmente, não é tarefa fácil tentar concatenar teorias diversas em uma categorização geral e global. Sem a explícita intenção de impor essa categorização, o QCER atingiu o objetivo de padronização por meio de seus descritores. E, apesar de sempre frisarem que o documento do QCER não tem um caráter normativo ou prescritivo, seria muito ingênuo acreditar nessa afirmação, uma vez que, como já comentado, todos os livros didáticos e cursos estão orientados para esses níveis e sua descrição. 
Vivemos o paradoxo de treinar o aluno para testes oficiais e para as formalidades e, ao mesmo tempo, de criar uma atmosfera "autêntica" no ambiente escolar ${ }^{23}$. Diante de nosso contexto, devemos nos perguntar se nosso aluno pode mesmo se movimentar na cultura linguística em questão e se, com o "arsenal linguístico" adquirido em sala, ele é capaz de compreender e apresentar conteúdos ${ }^{24}$.

Bleyhl (2003, p.39) salienta que partindo do princípio de que os alunos estão em processo interativo desde o início do aprendizado e que durante toda a vida se aprende uma língua, não se pode reduzir ou limitar tal processo ao aspecto formal linguístico exigido pelos testes, que não captam os momentos comunicativos reais, por exemplo: quando o aluno tem sucesso ao compreender uma informação, ao ser capaz de apresentar uma ideia ou discutir sobre ela.

A interação é, de fato, um aspecto de destaque no QCER, com papel central na comunicação (QCER, 2001, p.35). E aprender a interagir, segundo o QCER, significa mais do que "aprender a receber e a produzir enunciados" (Ibid., 36). Neste sentido, o esforço de determinar uma escala de níveis elementares não se justifica ao considerar a importância da interação, já que quando interagimos não passamos por categorias, aumentando em progressão vertical nossa proficiência. Com efeito, dificilmente teremos alunos-padrão seguindo grades de conhecimento vertical ou horizontalmente. O fato é que "toda ação linguística ocorre dentro de um contexto específico, sem o qual ela não existe" (BREDELLA, 2003, p.45). E este aspecto o QCER não tem condições de determinar.

Na verdade, o QCER ainda repete os discursos tradicionais em meio a vários novos termos da pesquisa atual ${ }^{25}$. A língua é vista como bem valioso a ser considerado, como se pudesse ser protegida e salva, como um tesouro, ao mesmo tempo e de forma paradoxal, o desenvolvimento de uma diversidade linguística deve servir para superar barreiras e preconceitos. Torna-se evidente, portanto, que por trás de todo esse discurso, está o jogo do poder político e linguístico.

\footnotetext{
${ }^{23}$ House (2003, p.97) comenta sobre o trabalho paradoxal do professor.

${ }^{24}$ Bleyhl $(2003,36)$ expõe sobre o olhar linguístico macroscópico e microscópico nas escolas. Como microscópico, o autor cita a atenção dada aos erros formais; como macroscópico, a capacidade do aluno de se movimentar no contexto linguístico e de utilizar o que aprendeu em sala, e critica a postura microscópica escolar.

"Der Blick darf in der Schule nicht mehr ausschliesslich auf das mikroskopische Detail des sprachlichen Atoms gerichtet werden - sprich darauf, dass nur die formalen Einzelfehler gebrandmarkt und addiert werden. Der Blick ist makroskopischer - auf die Fähigkeit zu richten, ob und wie der Lerner sich in der fremden Sprachkultur zu bewegen und zu behaupten weiss, ob und wie er mittels seines Sprachvermögens Inhalte erschliessen und darlegen kann.“

${ }^{25}$ Freundenstein (2003, p.77) usa o antigo dito popular como comparação: "vinho velho em novos tonéis" (Alter Wein wird in neu beschriftete Schläuche gefüllt).
} 
Tal processo competitivo das línguas no mercado $^{26}$ e as contradições do documento nos levam a refletir sobre nossa prática como professores: nós que determinamos com base em documentos definidos por um grupo em uma terra distante da nossa realidade o que nosso aluno deve aprender para desenvolver suas competências e capacidades comunicativas de acordo com seu contexto.

Atitudes importantes como a percepção da alteridade, buscando assim outros recursos - entre eles o code-switching, chunks, o uso da própria língua materna ou de uma terceira língua como língua franca e o uso de internacionalismos e palavras estrangeiras - com o objetivo de conseguir se comunicar e atingir seus objetivos na língua-alvo, são alguns dos aspectos desconsiderados no QCER ${ }^{27}$.

Autores como Christ (2003) e Edmonson (2003) levantam ainda a questão da terceira língua na comunicação. Edmonson (2003) afirma que o fato de A não falar a língua materna de B e B não falar a língua materna de A não significa que os indivíduos necessariamente terão uma barreira para a comunicação e interação. Daí a necessidade de abordar o ensino de línguas como algo além das fronteiras do idioma que se leciona.

Segundo Edmonson (2003, p.69):

\begin{abstract}
A principal tarefa da escola deveria ser: levar os jovens a conhecer e identificar as mais diferentes convenções comunicativas e a grande variedade linguística deste mundo, a partir de exemplos de línguas bem diferentes e, com isso, treinar uma consciência de aprendizado. ${ }^{28}$
\end{abstract}

Ao preparar o nosso aluno, com a criação de estratégias e uma consciência de aprendizado, oferecemos as primeiras ferramentas, as quais ele sempre poderá utilizar para montar o seu próprio conhecimento linguístico. Devemos sempre nos questionar: "o que os nossos alunos realmente devem aprender e para quê? Devemos observar do que nosso aluno precisa e o que ele gostaria de aprender. Precisamos aprender a diferenciar a necessidade individual e a competência linguística exigida nos padrões fixados (cf. EDMONSON, 2003, p.72).

\footnotetext{
${ }^{26}$ Calvet, Jean (1997) tece em seus trabalhos sobre o "comportamento" das línguas no mercado em meio a interesses políticos e econômicos.

${ }^{27}$ Christ (2003, p.65) expõe sobre o que falta no Quadro, como por exemplo, os esquemas comunicativos usados para compensar a falta de vocabulário. Edmonson (p.72f) expõe categorias que poderiam ser relevantes para os aprendizes: Email, Chat, flerte, piadas, Code-Switching, Motherese

28 "Die Hauptaufgabe der Schule sollte darin bestehen, junge Menschen mit der Vielfalt von Sprachen und mit unterschiedlichen Kommunikationskonventionen auf dieser Welt vertraut $\mathrm{zu}$ machen, ihnen exemplarischen Sprachkenntnisse einer kleinen Anzahl ganz unterschiedlicher Sprachen zu vermitteln und somit eine Sprachlernbewusstheit zu trainieren" (Tradução nossa)
} 
De certa maneira, ao adotar o QCER como um sistema de regras fixas para guiar nosso trabalho, sem questionamentos, repetimos o antigo discurso colonial, cujo objetivo é "apresentar o colonizado como uma população de tipos degenerados com base na origem racial de modo a justificar a conquista e estabelecer sistemas de administração e instrução" (BHABHA, 2010, p.105).

Em se tratando de nossa realidade brasileira e como Bohunovsky (2009, p.171) salienta: "se percebermos que, no Quadro, [há] sugestões didáticas não condizentes com a situação de ensino brasileira, isso não deve necessariamente nos conduzir à conclusão de que "falte" algo aqui, ou de que talvez ainda não tenhamos chegado onde se encontram os europeus hoje." Realmente, há uma forte tendência daquele que trabalha com a "língua do outro" de encarar-se como um impostor ${ }^{29}$, o não-autêntico, daí a necessidade de repetir padrões, para ser a cópia do outro, quase a mesma coisa, embora não o seja exatamente (cf. Bhabha, 2010, p.131).

Acreditamos ainda que, por vezes, os próprios professores não se dão conta da importância de seu papel no ensino de línguas estrangeiras. Para muitos alunos, o professor é a ponte e a fonte de informações sobre tudo o que envolve a língua a ser aprendida. E não se pode esquecer de que, em se tratando do ensino de línguas, não há como não refletir sobre a cultura, pois “quando se aborda a língua, a cultura já está ali”. Como Jordão (2006, p.6) salienta, é evidente que "língua e cultura são indissociáveis, e não apenas por uma questão de vontade: ambas são procedimentos interpretativos arbitrária e socialmente constituídos e legitimados, interdependentes e mutuamente influenciadores". O professor irá trabalhar necessariamente com a "cultura", ao ensinar a língua. O desafio será levantar, portanto, questões culturais para que se possa ir além dos estereótipos e dos discursos que promovem a fixidez.

\section{PERSPECTIVAS}

Neste trabalho, apresentamos os principais objetivos do QCER e tecemos, sobre ele, algumas críticas e reflexões. Discutimos ainda sobre o uso de termos como diversidade e sobre a visão de cultura exposta no documento. Constatamos por fim que,

\footnotetext{
${ }^{29}$ Referente ao professor impostor, Bernat (2008) pesquisa sobre a "síndrome do impostor", relatando sobre as dificuldades do professor não-nativo frente à língua que não é "sua". Também Halu (2010, p.96) comenta como professor não-nativo parece sempre tentar "equacionar seu status de falante não-nativo com sua função de transmitir conhecimento em sua disciplina, não sendo considerado legítimo 'proprietário’ da língua”.
} 
apesar de citarem a importância da compreensão do outro, não há um descritor que aborde esse tema ao longo do documento.

Realmente, é preciso dizer que sabemos o quanto é difícil taxar níveis de capacidades. Nós professores podemos até mesmo titubear diante das descrições do QCER referentes à nossa própria avaliação pessoal, sem poder definir claramente se somos capazes de realizar tudo que é previsto. Há muitos fatores envolvidos no aprendizado: personalidade, experiências do aprendiz, sucessos e insucessos, a percepção individual, enfim, momentos. Preparar nosso aluno para os possíveis momentos e seus entre-lugares, sem obrigá-lo a usar nossa visão para enxergar é o desafio que se lança a professores de língua no mundo todo.

Como conclusão, falamos sobre a importância do desenvolvimento de estratégias e do uso de recursos comunicativos para além de uma grade que determina passos fixos a serem dados: como o uso de chunks para se comunicar, o code-switching, o uso de uma língua franca ou de internacionalismos e latinismos para facilitar a interação.

Por fim, questionamos: "O que nos falta?"

Falta abrir nosso leque de opções na prática e refletir sobre os objetivos dentro de nosso contexto. Na realidade, se observarmos a descrição das capacidades, nem sempre podemos determinar com certeza se o aluno poderá atingir todos esses objetivos. Além disso, ao reduzir a língua a uma progressão determinada, impede-se que o aluno busque construir seu próprio caminho

O QCER, sem dúvida, conseguiu atingir um grande espectro de influência dentro do ensino de línguas, e o documento tem seu mérito pelo que propõe e pelas discussões que promoveu. Mas a questão ainda permanece: Como agir diante das constatações apresentadas?

Não temos a pretensão de apresentar a solução para todos os problemas levantados. Nosso intuito é dialogar, apresentar nossas considerações e refletir sobre nossa prática. Daqui para frente, são necessárias pesquisas para identificar que tipo de estratégias podem ser aplicadas para melhorar nossa prática, apesar das grades que nos cercam. Em suma, nós precisamos aprender a transformar o discurso autoritário na prática. No momento, temos a nossa parcela de responsabilidade na perpetuação de uma prática ruim, quando não analisamos nem pesquisamos sobre as consequências da introdução de parâmetros adotados. 
Como conclusão, acreditamos que o processo de aprendizado é muito particular e, por isso, dificilmente se encaixaria perfeitamente nesses seis níveis padronizados. $\mathrm{O}$ intuito das considerações apresentadas neste breve artigo é, por fim, levar o professor a pensar sobre soluções locais ao lidar com a adoção de metas e parâmetros não criados para sua realidade. Devemos partir da realidade local, do contexto específico de cada instituição ou profissional, e não de uma distante realidade europeia (se é que se pode falar sobre uma realidade europeia, uma vez que, dentro da própria Europa se percebe a dificuldade em manter ou criar padrões). Afinal, língua e cultura não são fixas e passíveis de categorização, assim como o processo de aprendizado de cada um, que acontece em cada espaço e no seu tempo.

\section{REFERÊNCIAS}

ALTMAYER, C. Sprachkultur und Mehrsprachigkeit: Neuerscheinungen zur europäischen Sprachenpolitik. Zeitschrift für Interkulturellen Fremdsprachenunterricht, 2004. Disponível em: <http://zif.spz.tu-darmstadt.de/jg-092/beitrag/Sprachenpolitik2.htm>. Acesso: 11.ago.2011.

BARKOWSKI, H. Skalierte Vagheit - der europäische Referenzrahmen für Sprachen und sein Versuch, die sprachliche Kommunikationskompetenz des Menschen für Anstiegen des Fremdsprachenunterrichts niveaugerecht zu portionieren. In: BAUSCH, K., CHRIST, H., KÖNIGS, F. Der Gemeinsame europäische Referenzrahmen für Sprachen in der Diskussion. Tübingen: G. Narr, 2003.

BAUSCH, K., CHRIST, H., KÖNIGS, F. Der Gemeinsame europäische Referenzrahmen für Sprachen in der Diskussion. Tübingen: G. Narr, 2003.

BERNAT, E. Towards a pedagogy of empowerment: the case of 'impostor syndrome' among pre-service non-native speaker teachers. In: TESOL. English Language Teacher Education and Development Journal, v.11, 2008. Disponível em: http://www.elted.net/issues/volume-11/1\%20Bernat.pdf. Acesso: 11.jan.2012.

BHABHA, Homi. O local da Cultura. Belo Horizonte: Editora UFMG, 2010.

BLEYHL, W. Die sprachliche Leistungsbeurteilung und die Chance zur Verbesserung des Fremdsprachenunterrichts dank des backwash-Effekts. In: BAUSCH, K., CHRIST, H., KÖNIGS, F. Der Gemeinsame europäische Referenzrahmen für Sprachen in der Diskussion. Tübingen: G. Narr, 2003.

BREDELLA, L. Lesen und Interpretieren im „Gemeinsamen europäischen Referenzrahmen für Sprachen“ die Missachtung allgemeiner Erziehungsziele. In: BAUSCH, K., CHRIST, H., KÖNIGS, F. Der Gemeinsame europäische Referenzrahmen für Sprachen in der Diskussion. Tübingen: G. Narr, 2003.

BOHUNOVSKY, R. O ensino de línguas estrangeiras no Brasil e a "compreensão do 
estrangeiro": o papel da tradução. Horizontes de Linguística Aplicada, v. 8, n.2, p. 170184,2009

CALVET, L.-J. As Políticas Linguísticas. São Paulo: Parábola, 2007.

CHRIST, H. Was leistet der, Gemeinsame europäische Referenzrahmen für Sprachen: lernen, lehren, beurteilen. In: BAUSCH, K., CHRIST, H., KÖNIGS, F. Der Gemeinsame europäische Referenzrahmen für Sprachen in der Diskussion. Tübingen: G. Narr, 2003.

EDMONSON, W. Bildungspolitik und Referenzrahmen. In: BAUSCH, K., CHRIST, H., KÖNIGS, F. Der Gemeinsame europäische Referenzrahmen für Sprachen in der Diskussion. Tübingen: G. Narr, 2003.

FOUCAULT, M. A ordem do discurso. São Paulo: Edições Loyola, 1996.

FREUNDENSTEIN, R. Richtlinien gehen, der Referenzrahmen kommt... Wie sich ineffektives Sprachenlernen durch neue Begriffe perpetuieren lässt. In: BAUSCH, K., CHRIST, H., KÖNIGS, F. Der Gemeinsame europäische Referenzrahmen für Sprachen in der Diskussion. Tübingen: G. Narr, 2003.

HALU, Regina. Formação de formadoras de professoras de inglês em contexto de formação continuada (NAP-UFPR). 2010. 247 f. Dissertação (Doutorado em Linguística) - Programa de Pós-Graduação em Letras, Universidade Federal do Paraná, Curitiba, 2010.

HOUSE, J. Der gemeinsame europäische Referenzrahmen für Sprachen - Anspruch und Realität. In: BAUSCH, K., CHRIST, H., KÖNIGS, F. Der Gemeinsame europäische Referenzrahmen für Sprachen in der Diskussion. Tübingen: G. Narr, 2003.

JORDÃO, C. M. O ensino de línguas estrangeiras - de código a discurso. In: VAZ BONI, V. (Org.). Tendências contemporâneas no ensino de línguas. União da Vitória: Kaigangue, 2006.

Revista $\quad 2000.2$ Brasil, Disponível
<http://revistabrasil.org/revista/ingles/clarissa.htm\#fn2>, 2000. Acesso em: 20.ago.2011.

A Postcolonial Framework for Brazilian EFL Teachers' Social Identities. Matice en Lenguas Extranjeras, n. 2, 2008a. Disponível em: <www.revistamatices.unal.edu.co>. Acesso em: 10.jul.2011.

PRAXEDES, C. Quadro Comum Europeu de ensino-aprendizagem e avaliação de línguas - o que falta ao Cone Sul para seguir este exemplar modelo de integração multicultural? Revista Philologus, n. 40 Disponível em: $<$ https://www.filologia.org.br/revista/40suple/quadro_comum_europeu.pdf $>$. Acesso em: 11.ago.2011.

QEVEHA, J. Parâmetros para o ensino, a aprendizagem e a avaliação de língua 
estrangeira moderna. Revista Trama, v. 4, n. 7, p. 125-130, $1^{\circ}$ Semestre de 2008.

CONSELHO EUROPEU. Quadro Europeu Comum de Referência para as línguas: aprendizagem, ensino e avaliação. Lisboa: Edições ASA, 2001. Disponível em: $<$ http://www.asa.pt/produtos/produto.php?id_produto=661536>.

QUETZ, J. Der Gemeinsame europäische Referenzrahmen: Ein Schatzkästlein mit Perlen, aber auch mit Kreuzen und Ketten. In: BAUSCH, K., CHRIST, H., KÖNIGS, F. Der Gemeinsame europäische Referenzrahmen für Sprachen in der Diskussion. Tübingen: G. Narr, 2003.

RUTHERFORD, J. O Terceiro Espaço: Uma entrevista com Homi Bhabha. Revista do Patrimônio Histórico e Artístico Nacional. Rio de Janeiro: v. 24, p. 35-41, 1996. 